\section{(A) Check for updates}

Cite this: Dalton Trans., 2018, 47 10692

Received 31st March 2018, Accepted 2nd June 2018

DOI: $10.1039 / \mathrm{c} 8 \mathrm{dt} 01262 \mathrm{~h}$

rsc.li/dalton

\title{
The modular synthesis of rare earth-transition metal heterobimetallic complexes utilizing a redox-active ligand $\dagger$
}

\author{
James R. Hickson, ${ }^{\text {a,b }}$ Samuel J. Horsewill, ${ }^{a}$ Christopher Bamforth, ${ }^{a}$ Jake McGuire, (DD a \\ Claire Wilson, (iD a Stephen Sproules (iD a and Joy H. Farnaby (iD *a
}

\begin{abstract}
We report a robust and modular synthetic route to heterometallic rare earth-transition metal complexes. We have used the redox-active bridging ligand 1,10-phenathroline-5,6-dione (pd), which has selective $N, N^{\prime}$ or $O, O^{\prime}$ binding sites as the template for this synthetic route. The coordination complexes $\left[\mathrm{Ln}(\mathrm{hfac})_{3}\left(N, N^{\prime}-\mathrm{pd}\right)\right](\mathrm{Ln}=\mathrm{Y}[\mathbf{1}], \mathrm{Gd}[\mathbf{2}] ;$ hfac = hexafluoroacetylacetonate) were synthesised in high yield. These complexes have been fully characterised using a range of spectroscopic techniques. Solid state molecular structures of $\mathbf{1}$ and $\mathbf{2}$ have been determined by X-ray crystallography and display different pd binding modes in coordinating and non-coordinating solvents. Complexes $\mathbf{1}$ and $\mathbf{2}$ are unusually highly coloured in coordinating solvents, for example the vis-NIR spectrum of $\mathbf{1}$ in acetonitrile displays an electronic transition centred at $587 \mathrm{~nm}$ with an extinction coefficient consistent with significant charge transfer. The reaction between 1 and $\mathbf{2}$ and $V C p_{2}$ or $\mathrm{VCp}_{2}^{t}\left(\mathrm{Cp}^{\mathrm{t}}=\right.$ tetramethylcyclopentadienyl) resulted in the isolation of the heterobimetallic complexes, [ $\left.\mathrm{Ln}(\mathrm{hfac})_{3}\left(N, N^{\prime}-O, O^{\prime}-\mathrm{pd}\right) \mathrm{VC} \mathrm{p}_{2}\right](\mathrm{Ln}=\mathrm{Y}$ [3], Gd [4]) or $\left[\mathrm{Ln}(\mathrm{hfac})_{3}\left(\mathrm{~N}_{1} \mathrm{~N}^{\prime}-\mathrm{O}, \mathrm{O}^{\prime}-\mathrm{pd}\right) \mathrm{VCp_{2 } ^ { \mathrm { t } }}\right.$ ] $(\mathrm{Ln}=\mathrm{Y}[\mathbf{5}], \mathrm{Gd}[\mathbf{6}])$. The solid state molecular structures of $\mathbf{3}, \mathbf{5}$ and $\mathbf{6}$ have been determined by $\mathrm{X}$-ray crystallography. The spectroscopic data on 3-6 are consistent with oxidation of $\mathrm{V}(\mathrm{II})$ to $\mathrm{V}(\mathrm{IV})$ and reduction of $\mathrm{pd}$ to $\mathrm{pd}^{2-}$ in the heterobimetallic complexes. The spin-Hamiltonian parameters from low temperature X-band EPR spectroscopy of $\mathbf{3}$ and $\mathbf{5}$ describe a ${ }^{2} \mathrm{~A}_{1}$ ground state, with a $V$ (IV) centre. DFT calculations on $\mathbf{3}$ are in good agreement with experimental data and confirm the SOMO as the $d_{x^{2}-y^{2}}$ orbital localised on vanadium.
\end{abstract}

\section{Introduction}

The cooperativity between metal centres in multimetallic complexes, clusters and polymeric species gives rise to very remarkable chemistry in a diverse range of fields. ${ }^{1}$ The potential applications of complexes containing both transition metals and lanthanides are significant. In particular there is research interest in the design of rare earth-transition metal singlemolecule magnets (SMM) and catalysts. ${ }^{2,3}$

The chemistry of multimetallic complexes containing f-elements is significantly less well developed than that of transition metals. This is attributable to the fact that the directed synthesis of $\mathrm{f}-\mathrm{d}$ complexes is non-trivial. The inspiration for our approach was the $\mathrm{Tb}$ analogue of the $\left[\left\{\left(\mathrm{SiMe}_{3}\right)_{2} \mathrm{~N}\right\} \mathrm{Ln}\right]_{2} \mathrm{~N}_{2} \mathrm{~K}$ system. This complex was remarkable both for the $\left(\mathrm{N}_{2}\right)^{3 \cdot-}$

${ }^{a}$ School of Chemistry, WestCHEM, University of Glasgow, Glasgow, UK. E-mail: Joy.Farnaby@glasgow.ac.uk

${ }^{b}$ Department of Chemistry, Imperial College London, South Kensington, London, UK $\dagger$ Electronic supplementary information (ESI) available. CCDC 1832429-1832434 and 1841191. For ESI and crystallographic data in CIF or other electronic format see DOI: $10.1039 / \mathrm{c} 8 \mathrm{dt} 01262 \mathrm{~h}$ anion and the SMM behaviour. ${ }^{4}$ It generated significant subsequent interest in multimetallic lanthanide radical bridged complexes. ${ }^{5}$ The very recent reports of magnetic hysteresis at $60 \mathrm{~K}$ in a dysprosocenium cation are a testament to the power of the organometallic molecular design approach. ${ }^{6,7}$

Our aim was to identify and use a redox-active bridging ligand with multiple and selective binding sites as the template for a general and modular synthetic route to heterometallic $\mathrm{d}-\mathrm{f}$ or $\mathrm{f}-\mathrm{f}^{\prime}$ complexes. The ligand used in this work 1,10phenathroline-5,6-dione (pd) has been predominantly studied for its physical organic, biological and bio-inorganic chemistry, particularly as a precursor to DNA intercalation agents and photocatalysts. ${ }^{8,9}$ Metal complexes of pd have been targeted for applications as diverse as electrocatalysis, sensitised Ln emission and thermochromism. ${ }^{10-12}$

There is transition metal literature precedent for using pd as a bridging ligand to synthesise multi-metallic complexes. The first transition metal complexes of pd were synthesised by Balch by the addition of $\mathrm{Pt}\left(\mathrm{PPh}_{3}\right)_{4}$ to pd to form $\left[\left(O, O^{\prime}-\mathrm{pd}\right) \mathrm{Pt}\right.$ $\left.\left(\mathrm{PPh}_{3}\right)_{2}\right] \cdot{ }^{13}$ The electrochemical and electrocatalytic properties of these complexes were subsequently investigated by Abruna. $^{10}$ Pierpont demonstrated that $\left[\left(O, O^{\prime}-\mathrm{pd}\right) \mathrm{Pt}\left(\mathrm{PPh}_{3}\right)_{2}\right]$ 

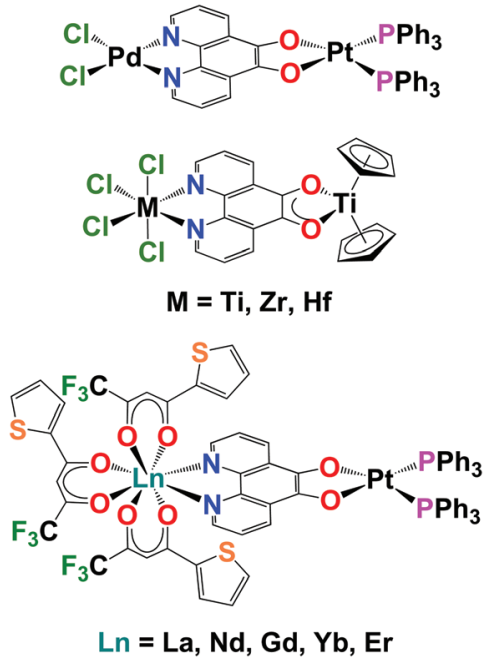

Chart 1 Bimetallic complexes of pd.

could be used as a bipyridine equivalent to bind a second metal. ${ }^{14}$ This paper also reported the selective $N, N$ '-pd binding of $\mathrm{PdCl}_{2}$ and the first crystal structures of transition metal pd complexes (Chart 1). Eisenberg combined pd and bipyridine (bipy) to form the homobimetallic Pt complexes, $\left[\mathrm{PtCl}_{2}\left(N, N^{\prime}-O, O^{\prime}-\mathrm{pd}\right) \mathrm{Pt}(\mathrm{di}-\right.$ tert-butyl-bipy)]. These were then used as precursors to synthesise $\left[\mathrm{Pt}(\mathrm{L})\left(N, N^{\prime}-O, O^{\prime}\right.\right.$-pd)Pt(di-tert-butyl-bipy) $]$ (where $\mathrm{L}=$ dithiolate, dicatecholate or $\mathrm{pd}$ ) and probe electronic structure. ${ }^{15}$

Directly relevant to this work, is the first report of the coordination and redox chemistry of group 4 and 5 metals with pd, by Pampaloni and Calderazzo. ${ }^{16}$ These groups subsequently published a number of studies demonstrating that pd will selectively bind $N, N^{\prime}$ with a coordination chemistry precursor or $O, O^{\prime}$ with a reducing organometallic precursor and can form homo- and heterometallic transition metal complexes. ${ }^{17-19}$ Prior to this work there are just two reports of structurally characterised molecular lanthanide complexes of pd, both by Faulkner and Ward, which describe the sensitised NIR emission of $\left[\mathrm{Ln}(\mathrm{tta})_{3}\left(N, N^{\prime}-O, O^{\prime}-\mathrm{pd}\right) \mathrm{Pt}\left(\mathrm{PPh}_{3}\right)_{2}\right](\mathrm{Ln}=\mathrm{La}, \mathrm{Nd}$, $\mathrm{Gd}, \mathrm{Er}, \mathrm{Yb} ; \mathrm{tta}=1$-thenoyl-5,5,5-trifluoroacetylacetonate). ${ }^{12,20}$ We note that there are reports of the biological activity of combinations of Ln and pd.

Here we report a robust and modular synthesis and first structural characterisation of $\left[\operatorname{Ln}(\mathrm{hfac})_{3}\left(N, N^{\prime}-\mathrm{pd}\right)\right](\operatorname{Ln}=\mathrm{Y}, \mathrm{Gd})$ complexes. We also report the reduction of these coordination chemistry complexes using vanadocenes to form heterobimetallic rare earth-transition metal complexes. The $\left[\operatorname{Ln}(\text { hfac })_{3}\left(N, N^{\prime}-O, O^{\prime}\right.\right.$-pd $\left.) \mathrm{VCp}^{\mathrm{R}}{ }_{2}\right]$ complexes have been fully characterised by a range of spectroscopic techniques. These complexes are spectroscopically rich and represent the first building-blocks in our studies of rare earth-transition metal complexes.

\section{Results and discussion}

\section{Synthesis of $\left[\operatorname{Ln}(h f a c)_{3}\left(N, N^{\prime}-p d\right)\right]$}

Metal precursor choice is particularly important in f-element chemistry. In this work, we chose to use the $\operatorname{Ln}(\mathrm{OTf})_{3}(\mathrm{Ln}=\mathrm{Y}$, $\mathrm{Gd}$, OTf $=\mathrm{CF}_{3} \mathrm{SO}_{3}$ ) more commonly applied in organic synthesis as Lewis acid catalysts. ${ }^{21}$ This was due to the ease of preparation from inexpensive $\mathrm{Ln}_{2} \mathrm{O}_{3}$ starting materials, their stability in $\mathrm{H}_{2} \mathrm{O}$ and facile dehydration by comparison to commercially available $\operatorname{LnCl}_{3} \cdot\left(\mathrm{H}_{2} \mathrm{O}\right)_{x}$. The hfac (hfac $=1,1,1-5,5,5-$ hexafluoroacetylacetonate) ligand was chosen because $\left[\operatorname{Ln}(\text { hfac })_{3}(\right.$ glyme $\left.)\right]$ are well-defined molecular species. ${ }^{22,23}$ The hfac ancillary ligand environment has good solubility and stability, with ${ }^{19} \mathrm{~F}$ NMR as an additional probe of solution behaviour. We note that while you can access $\left[\operatorname{Ln}(\mathrm{hfac})_{3}\right.$ (glyme)] directly from $\operatorname{Ln}_{2} \mathrm{O}_{3}$, the synthesis requires the addition of chelating polyethers to prevent aggregation. ${ }^{24}$

However, using a salt elimination reaction enables this synthetic route to be modular and applicable to other ligand environments. The coordination complexes $\left[\operatorname{Ln}(\mathrm{hfac})_{3}\left(N, N^{\prime}-\right.\right.$ pd)] were synthesised in high yield. $\operatorname{Ln}(\mathrm{OTf})_{3}(\mathrm{Ln}=\mathrm{Y}, \mathrm{Gd})$, pd and 3 equivalents of $\mathrm{K}(\mathrm{hfac})$ were combined dry, and THF added at room temperature with stirring, giving a colour change from yellow to deep green. The reaction was stirred at room temperature for $16 \mathrm{~h}$, and $\mathrm{THF}$ removed in vacuo. Extraction into toluene, filtration to exclude K(OTf) and removal of toluene in vacuo gave the neutral complexes $\left[\operatorname{Ln}(\mathrm{hfac})_{3}\left(N, N^{\prime}\right.\right.$-pd) $]$ as pastel green solids in excellent yields (Ln = Y: 82\% [1], Gd: 79\% [2]) (Scheme 1). Elemental analyses of 1 and 2 crystallised from toluene at $-35{ }^{\circ} \mathrm{C}$ support the $\left[\operatorname{Ln}(\mathrm{hfac})_{3}\left(N, N^{\prime}-\mathrm{pd}\right)\right]$ formulation, with one toluene of crystallisation associated. $\mathbf{1}$ and $\mathbf{2}$ are soluble in both coordinating and non-coordinating solvents, to give green and yellow solutions, respectively.
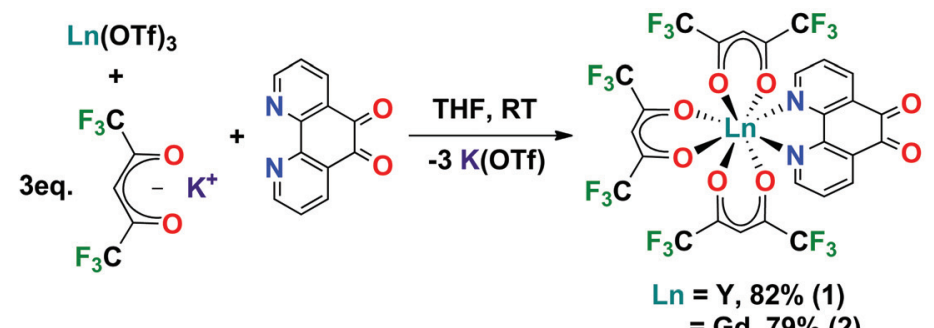

$=\mathrm{Gd}, 79 \%(2)$

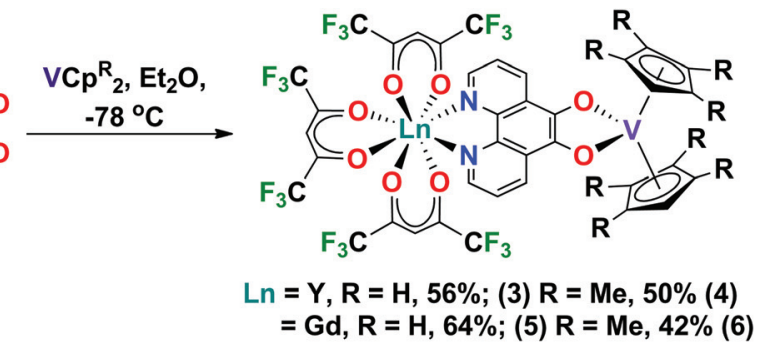

Scheme 1 The modular synthesis of rare earth-transition metal complexes. 


\section{Spectroscopy of $\left[\operatorname{Ln}(\mathrm{hfac})_{3}\left(N, N^{\prime}-\mathrm{pd}\right)\right]$}

The room temperature ${ }^{1} \mathrm{H}$ NMR spectrum of 1 in $d_{6}$-benzene is consistent with complexation to form the $1: 1$ adduct. The pd resonances in 1 at $\delta=6.37,7.53$, and $9.16 \mathrm{ppm}$ are shifted downfield relative to the pd free ligand and the aromatic splitting pattern (dd) is no longer observed for the protons neighbouring the $N, N^{\prime}$-pocket. The expected ratio of $2: 2: 2: 3$ is observed between the pd resonances and the hfac singlet at $\delta=$ $6.23 \mathrm{ppm}$. The ${ }^{19} \mathrm{~F}$ NMR spectrum displays a singlet at $\delta=$ $-76.9 \mathrm{ppm}$. The X-band EPR spectrum of 2 at room temperature (see $\mathrm{ESI} \dagger$ ) is common for $\mathrm{Gd}(\mathrm{III})$ and simulation gave $g_{\text {iso }}=$ 1.989 , close to that of the free electron, which is typical for Gd(III). ${ }^{25}$ The ${ }^{8} \mathrm{~S}_{0}$ ground state of Gd(III) has no angular orbital momentum, and so unlike its f-block counterparts, Gd(III) gives an EPR response at room temperature. The Evans Method was used to determine the magnetic moment of 2 in $d_{8}$-thf at room temperature. The corrected magnetic moments are in the range of $7.56-7.71 \mu_{\mathrm{B}}$ for 2 , consistent with $\mathrm{Gd}(\mathrm{III})$.

IR spectroscopy cannot definitively assign the coordination mode of the pd ligand but does provide a useful measure of its carbon-oxygen bond order. The reported ranges of $\nu_{\mathrm{CO}}$ are: neutral pd $=1678 \mathrm{~cm}^{-1}$, radical anion $\mathrm{pd}^{-0} 1500-1400 \mathrm{~cm}^{-1}$ and dianion $\mathrm{pd}^{2-} 1400-1300 \mathrm{~cm}^{-1} \cdot{ }^{14,16}$ The IR spectra of 1 and 2 have several absorptions in the $\nu_{\mathrm{CO}}$ region, complex 1 at 1699, 1668 and $1647 \mathrm{~cm}^{-1}$ and 2 at 1697, 1661, $1647 \mathrm{~cm}^{-1}$. The $\nu_{\mathrm{CO}}$ at 1647 is assigned to the hfac ligand based on the IR of closely related complexes, $\left[\mathrm{Ln}(\mathrm{hfac})_{3}\right.$ (glyme)], which have very strong absorption between 1650 and $1660 \mathrm{~cm}^{-1} \cdot{ }^{23}$ The $\nu_{\mathrm{CO}}$ at 1699 and $1697 \mathrm{~cm}^{-1}$ are assigned as $N, N^{\prime}$-pd. This is consistent with complexes formulated as, $\left[\operatorname{PdCl}_{2}\left(N, N^{\prime}-\mathrm{pd}\right)\right],{ }^{13}\left[\mathrm{Fe}\left(N, N^{\prime}-\right.\right.$ pd $\left.)_{3}\right]\left[\mathrm{PF}_{6}\right]_{2},{ }^{10}$ and $\left[\mathrm{MCl}_{4}\left(N, N^{\prime}-\mathrm{pd}\right)\right](\mathrm{M}=\mathrm{Ti}, \mathrm{Zr}, \mathrm{Hf})^{16}$ which have strong absorptions in the range $1680-1705 \mathrm{~cm}^{-1}$. We propose additionally that the $\nu_{\mathrm{CO}}$ at 1668 and $1661 \mathrm{~cm}^{-1}$ may result from the short contacts seen between the Ln metal centre and one pd-O atom of the neighbouring molecule (Fig. 3 and $\operatorname{ESI}_{\dagger} \dagger$ ).

The deep green colour of $\mathbf{1}$ and $\mathbf{2}$ in coordinating solvents is an unexpected property as neither $4 \mathrm{~d}^{0} \mathrm{Y}(\mathrm{III})$ nor $4 \mathrm{f}^{7} \mathrm{Gd}(\mathrm{III})$ often give rise to strongly coloured complexes. It is of note that related Ln complexes with 1,10-phenanthroline (phen) or neutral 2,2-bipyridyl (bipy) ligands are not strongly coloured. ${ }^{24,26,27}$ The electronic spectra of $\mathbf{1}$ and 2 in acetonitrile display peaks centred at $587 \mathrm{~nm}\left(\varepsilon=2390 \mathrm{M}^{-1} \mathrm{~cm}^{-1}\right)$ and $597\left(\varepsilon=129 \mathrm{M}^{-1} \mathrm{~cm}^{-1}\right)$, respectively (see ESI $\uparrow$ for spectra). We assign this as ligand to metal charge transfer.

\section{Crystallography of $\left[\operatorname{Ln}(\text { hfac })_{3}\left(N, N^{\prime}-\right.\right.$ pd $\left.)\right]$}

Crystals of 1 suitable for X-ray diffraction were grown from either a saturated $\mathrm{Et}_{2} \mathrm{O}$ solution at $-35{ }^{\circ} \mathrm{C}$ over 7 days (1a) or a saturated toluene solution at $-15^{\circ} \mathrm{C}$ overnight (1b). Similarly crystals of 2 suitable for X-Ray diffraction were grown from either a saturated $\mathrm{Et}_{2} \mathrm{O}$ solution at $-35^{\circ} \mathrm{C}$ overnight (2a) or a saturated toluene solution at $-15{ }^{\circ} \mathrm{C}$ overnight (2b). The solid state molecular structures and selected parameters are shown in Fig. $1-3$ or in the ESI. $\dagger$

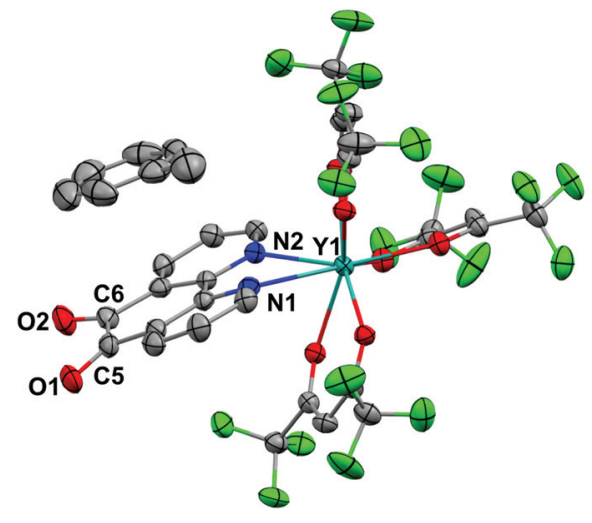

Fig. 1 Molecular structure of $1 \mathrm{~b}$. Hydrogen atoms omitted for clarity. Thermal ellipsoids drawn at $50 \%$ probability. Selected distances (Å): Y1-N1 2.501(3), Y1-N2 2.552(3), C5-C6 1.524(6), C6-O2 1.216(5), C5-O1 1.213(5).

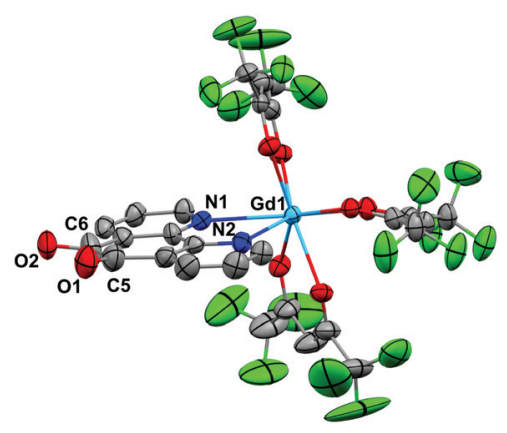

Fig. 2 Molecular structure of 2a. Hydrogen atoms and $\mathrm{Et}_{2} \mathrm{O}$ of crystallisation omitted for clarity. Thermal ellipsoids drawn at $50 \%$ probability. Selected distances (Å): Gd1-N1 2.585(8), Gd1-N2 2.555(9), C5-C6 1.54(6), C6-O2 1.23(2), C5-O1 1.24(2).

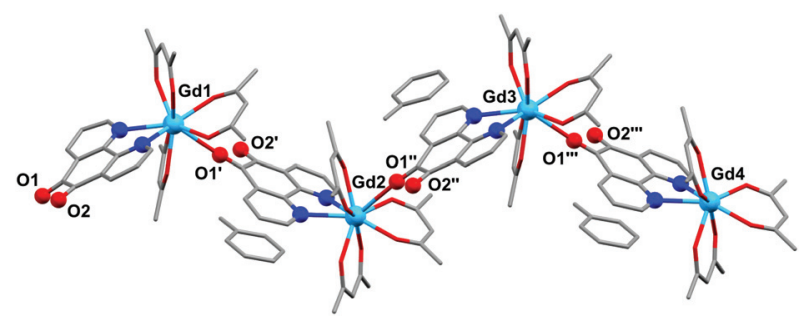

Fig. 3 Molecular structure of $\mathbf{2 b}$, showing the polymeric structure. All atoms depicted as wireframe or ball and stick.

All structures adopt a distorted square antiprismatic geometry, and confirm $N, N^{\prime}$-pd coordination. As expected the pd C-O distances in $\mathbf{1} \mathbf{a}-\mathbf{2 b}$ are unchanged from the free ligand (1.213(5) and 1.216(5) $\AA$ ). ${ }^{28}$ The Ln-O(hfac) distances to the hfac ligands are consistent between both structures, and are in agreement with the crystal structures of other examples of $\mathrm{Ln}(\mathrm{hfac})_{3}$ complexes in the range of $2.299(2)-2.343(3) \AA^{23,29}$ The $\mathrm{Ln}-\mathrm{N}(\mathrm{pd})$ distances in structures 1a-2b of 2.501(3)-2.585 (8) $\AA$ are directly comparable to those reported in $\left[\mathrm{Ln}(\mathrm{tta})_{3}\right.$ 
$\left.\left(N, N^{\prime}-O, O^{\prime}-p d\right) P t\left(\mathrm{PPh}_{3}\right)_{2}\right](\mathrm{Ln}=\mathrm{Er}, \mathrm{Gd} ;$ tta $=1$-thenoyl-5,5,5trifluoroacetylacetonate) of 2.499(7)-2.539(7) $\AA{ }^{12}$ as the ionic radius of $\operatorname{Er}(\mathrm{III})$ is an appropriate size match for $\mathrm{Y}(\mathrm{III}) .^{30}$ Complex $\mathbf{1}$ is the first crystallographically characterised example of an yttrium pd complex. The $\mathrm{Y}-\mathrm{N}(\mathrm{pd})$ distances are also comparable to those seen in $\left[\mathrm{Y}\left(\mathrm{pyrMe}_{2} \text {-acac }\right)_{3}(\mathrm{phen})\right]$ $\left(\right.$ pyrMe $_{2}$-acac $=1,5$-(1,3-dimethyl- $1 H$-pyrazol-4-yl)acetylacetonate) of 2.562(4)-2.579(4) $\AA^{24}$

The structure of $\mathbf{2} \mathbf{b}$ from toluene is a coordination polymer as a result of $N, N^{\prime}-O$-pd binding to the next Gd in the chain (Fig. 3). The only other structure in the CCDC that displays this binding mode is the $\mathrm{Ag}(\mathrm{I})$ coordination polymer $\left[\mathrm{Ag}\left(\mathrm{ClO}_{4}\right)\right.$ $\left.\left(N, N^{\prime}-O-p d\right)\right]_{n}{ }^{31}$ The Gd1-O2 distance is $2.830(2) \AA$, and the coordination polymer exhibits a zig-zag structure with an angle of $77.56^{\circ}$ between Gd-pd planes. Analysis of short contacts in 1b reveals a Y1-O2 interaction within the sum of the van der Waals radii at $3.154 \AA$, giving a pseudo-coordination polymer structure with an angle of $83.98^{\circ}$ between Y-pd planes (see ESI $\dagger$ ). As a result of the $N, N^{\prime}-O$-pd binding, both $2 \mathbf{b}$ and $\mathbf{1 b}$ feature significant distortion within the pd ring. The three rings of pd are no longer coplanar and there is an out-of-plane O2-ring distortion and associated out-of-plane displacement of $\mathrm{O} 2$.

\section{Reduction chemistry of 1 and 2}

The pd ligand can be sequentially reduced by two electrons, first to the semiquinone radical anion $\mathrm{pd}^{{ }^{-}}$and then to the fully reduced and diamagnetic catecholate $\mathrm{pd}^{2-}$; the reduction potentials are -0.85 and $-1.71 \mathrm{~V} v s$. $\mathrm{Fc}^{+} / \mathrm{Fc}$, respectively. ${ }^{10,32}$ Almost all published metal complexes of the reduced pd ligand contain $\mathrm{pd}^{2-}$ and the few examples of the radical anion of $\mathrm{pd}^{{ }^{--}}$were generated in situ, usually under electrochemical conditions and characterised by electronic spectroscopies such as EPR and UV-vis-NIR. This is in spite of the ease of reduction of pd to $\mathrm{pd}^{--}$relative to the structurally related 1,10-phenanthroline ${ }^{10}$ and 2,2'-bipyridine. ${ }^{33}$

Complex 1 is unstable under standard electrochemical conditions. Therefore, we used the reduction potentials of the free pd ligand to rationalise the choice of organometallic reducing agent. ${ }^{34}$ The first reversible oxidation process of V(II) to V(III) in $\mathrm{VCp}_{2}$ to $\mathrm{VCp}_{2}{ }^{+}$is a good match at $-0.93 \mathrm{~V} v s . \mathrm{Fc}^{+} / \mathrm{Fc}^{35}$ We note that $\mathrm{VCp}_{2}$ has been previously shown to reduce pd, with the product formulated as $\left[\left(O, O^{\prime}-\mathrm{pd}\right) \mathrm{VCp}_{2}\right]$ and in our hands this reaction formed intractable dark green solids. ${ }^{16}$ Additionally, we used a substituted vanadocene, $\operatorname{VCp}_{2}^{\mathrm{t}}\left(\mathrm{Cp}^{\mathrm{t}}=\right.$ tetramethylcyclopentadienyl) to test whether the added steric bulk would promote the formation of an ion pair. The substituted $\mathrm{Cp}^{\mathrm{t}}$ ligand environment is also a good model for extending this synthetic route to incorporate f-element organometallics. ${ }^{36}$

\section{Synthesis of $\left[\operatorname{Ln}(\mathrm{hfac})_{3}\left(N, N^{\prime}-O, O^{\prime}-\mathbf{p d}\right) \mathrm{VCp}^{\mathrm{R}}{ }_{2}\right]$}

A Schlenk flask charged with $\mathbf{1}$ or $\mathbf{2}$ and $\mathrm{VCp}_{2}$ was cooled to $-78{ }^{\circ} \mathrm{C}$ and $\mathrm{Et}_{2} \mathrm{O}$ was added with stirring. The colour of the resultant solution was dark green-black. The reaction mixture was warmed to room temperature and $\mathrm{Et}_{2} \mathrm{O}$ was removed in vacuo. Recrystallisation of the solids from a mixture of toluene and hexane at $-15{ }^{\circ} \mathrm{C}$ gave $\left[\operatorname{Ln}(\mathrm{hfac})_{3}\left(N, N^{\prime}-O, O^{\prime}\right.\right.$-pd $)$ $\mathrm{VCp}_{2}$ ] as black microcrystalline solids ( $\mathrm{Ln}=\mathrm{Y}: 56 \%[3], \mathrm{Ln}=$ Gd: 64\% [4]). The analogous reaction between 1 or 2 and $\mathrm{VCp}_{2}^{\mathrm{t}}$ $\left(\mathrm{t}=\mathrm{Me}_{4}\right)$, resulted in the isolation of dark green-black microcrystalline solids of $\left[\mathrm{Ln}(\mathrm{hfac})_{3}(N, N-O, O-\mathrm{pd}) \mathrm{VCp}_{2}^{\mathrm{t}}\right](\mathrm{Ln}=\mathrm{Y}$ : $50 \%,[5]$ Ln = Gd: 42\% [6]) (Scheme 1). The composition and purity of complexes 4-6 was confirmed by elemental analysis.

\section{Spectroscopy of $\left[\operatorname{Ln}(\mathrm{hfac})_{3}\left(N, N^{\prime}-O, O^{\prime}-\mathrm{pd}\right) \mathrm{VCp}^{\mathrm{R}}{ }_{2}\right]$}

Complexes 3-6 are paramagnetic and NMR silent. The Evans Method was used to determine the magnetic moment of 3, 5 and 6, in $d_{8}$-thf at room temperature. The corrected magnetic moments are in the range of $1.71-1.74 \mu_{\mathrm{B}}$ for $3,1.72-1.75 \mu_{\mathrm{B}}$ for 5 and $7.99-8.41 \mu_{\mathrm{B}}$ for $\mathbf{6}$. The data for 3 and 5 are consistent with a single unpaired electron i.e. $3 \mathrm{~d}^{1} \mathrm{~V}(\mathrm{IV})$, resulting from the oxidative addition of $\mathrm{V}(\mathrm{II})$ to $\mathrm{V}(\mathrm{IV})$ and the concomitant reduction of pd by two electrons to $\mathrm{pd}^{2-}$. The data for 6 are consistent with the value predicted by the spin only formula for Gd(III) and V(IV). This is chemical behaviour similar to the oxidative addition of $\mathrm{VCp}_{2}$ to acetylene to form the metallocyclopropane. ${ }^{37}$

The IR spectra of complexes 3-6, are consistent with pd reduction. The $\nu_{\mathrm{CO}}$ at 1699 and $1697 \mathrm{~cm}^{-1}$ assigned to neutral $N, N^{\prime}$-pd and at 1668 and $1661 \mathrm{~cm}^{-1}$ assigned to $N, N^{\prime}-O-$-pd are no longer visible. Instead, complexes 3-6, display $\nu_{\mathrm{CO}}$ in the range $1370-1381 \mathrm{~cm}^{-1}$, consistent with the reported examples of $\mathrm{pd}^{2-}$ complexes. ${ }^{14,16}$

An overlay of the electronic spectra of 3 and $\mathbf{4}$ collected in $\mathrm{MeCN}$ are contrasted with the electronic spectra of 5 and $\mathbf{6}$ collected in THF and presented in Fig. 4. The d-d transitions at

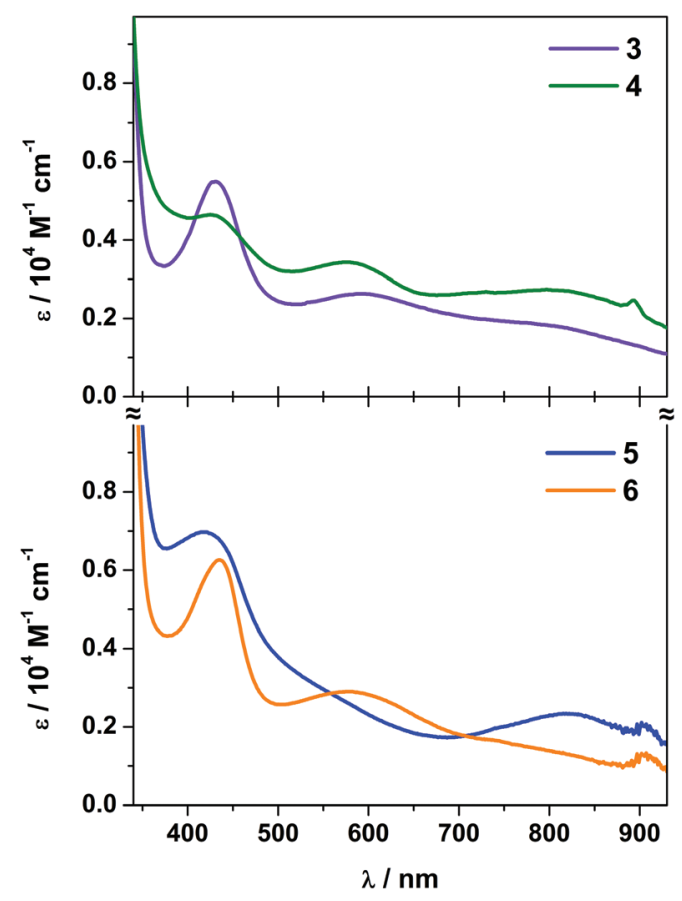

Fig. 4 Overlay of the electronic spectra of 3 and 4 in MeCN (top) and 5 and 6 in THF (bottom) recorded at room temperature. 
740 and $640 \mathrm{~nm}$ usually present in pseudo-tetrahedral vanadocenes $^{38,39}$ are not directly observed as they are hidden underneath the charge transfer transitions. The transitions are assigned with the aid of computational analysis (vide infra).

\section{Crystallography of $\left[\mathrm{Ln}(\mathrm{hfac})_{3}\left(N, N^{\prime}-O, O^{\prime}-\mathrm{pd}\right) \mathrm{VCp}^{\mathrm{R}}{ }_{2}\right]$}

Crystals of 3, 5 and 6 suitable for X-ray diffraction were grown by diffusion of hexane vapour into a toluene or $\mathrm{Et}_{2} \mathrm{O}$ solution at $-35{ }^{\circ} \mathrm{C}$ or by cooling a toluene/hexane mixture to $-35^{\circ} \mathrm{C}$ over several days. The structures and selected structural parameters are shown in Fig. 5 and 6 or in the ESI. $\dagger$ Complexes 3, 5 and 6 feature yttrium or gadolinium in a distorted square antiprismatic geometry and $N, N^{\prime}$-pd bound analogous to $\mathbf{1 a}$ and $2 \mathbf{a}$. The $\operatorname{VCp}^{\mathrm{R}}{ }_{2}$ units are $O, O^{\prime}$-pd bound, resulting in a pseudo-tetrahedral geometry typical for V(Iv) metallocenes. ${ }^{40,41}$ The metal to ancillary ligand bonding metrics are normal. The five membered ring formed between the $\mathrm{V}$ and the $O, O$ '-pocket of the pd

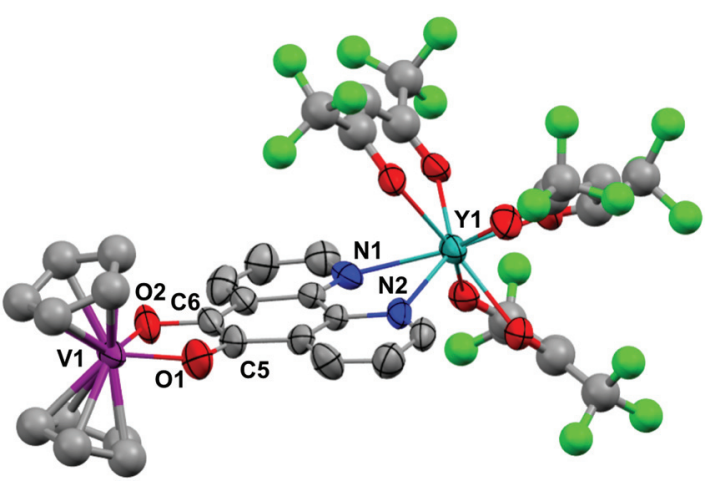

Fig. 5 Molecular structure of 3 . Hydrogen atoms and solvent of crystallisation omitted for clarity. Thermal ellipsoids drawn at 50\% probability for $\mathrm{pd}, \mathrm{V}$ and $\mathrm{Y}$. Other ancillary ligand atoms depicted as ball and stick due to $\mathrm{CF}_{3}$ and $\mathrm{Cp}$ disorder (see cif). Selected distances (Å): $\mathrm{Y} 1-\mathrm{N} 1$ 2.474(17), Y1-N2 2.482(17), C5-C6 1.396(15), C6-O2 1.24(2), C5-O1 $1.40(2), \mathrm{V} 1-\mathrm{O} 1$ 1.972(16), V1-O2 1.971(16).

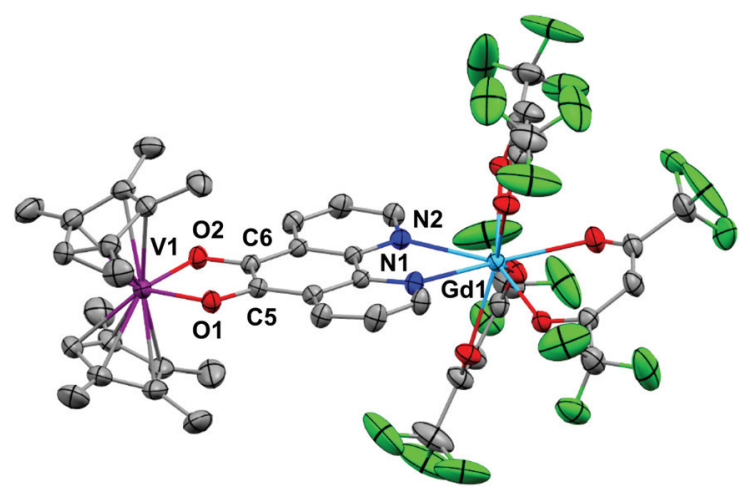

Fig. 6 Molecular structure of 6 . Hydrogen atoms and solvent of crystallisation omitted for clarity. Thermal ellipsoids drawn at $50 \%$ probability. Selected distances (Å) for 5: Y1-N1 2.48(1), Y1-N2 2.49(1), C5-C6 1.38(2), C6-O2 1.35(1), C5-O1 1.34(2), V1-O1 1.975(8), V1-O2 1.977(9) and 6: Gd1-N1 2.532(2), Gd1-N2 2.527(2), C5-C6 1.387(3), C6-O2 1.333(3), C5-O1 1.333(3), V1-O1 1.9869(18), V1-O2 1.9862(18). is a common structural motif. The V1-O1 and V1-O2 distances in 3, 5 and $\mathbf{6}$ are consistent with those observed in related complexes $\left[\mathrm{Na}_{2}\left(\mathrm{Et}_{2} \mathrm{O}\right)_{2}\right]\left[\mathrm{V}\left(\{\text { dippCO }\}_{2}\right)_{3}\right],\left[\mathrm{VCp}_{2}(\mathrm{acac})\right][\mathrm{OTf}]$ and $\mathrm{V}(\mathrm{Iv})$ catecholates such as $\left[\mathrm{NHEt}_{3}\right]_{2}\left[\mathrm{~V}(\mathrm{cat})_{3}\right]$ and $\left[\mathrm{H}_{2} \mathrm{PrDA}\right]\left[\mathrm{VO}(\mathrm{cat})_{2}\right]$ (cat = 1,2-dihydroxybenzene, $\operatorname{PrDA}=1,3$-diaminopropane). ${ }^{42-45}$

The metrics that are important in assessing the reduction of the pd ligand are $\mathrm{C} 5-\mathrm{C} 6, \mathrm{C} 5-\mathrm{O} 1$ and $\mathrm{C} 6-\mathrm{O} 2$. The C5-C6 bond distances in 3 of 1.40(3) $\AA$, in 5 of 1.38(2) $\AA$ and in 6 of 1.387(3) A are significantly shortened from that of $\mathbf{1 b}$ (1.524(6) $\AA$ ) consistent with double bond formation. The C5-O1 and C6-O2 distances in 3 of 1.40(2) and 1.24(2) $\AA$, in 5 of 1.34(2) and 1.35(2) $\AA$ and in 6 of 1.333(3) $\AA$ are significantly elongated from $1 \mathbf{b}(1.213(5)$ and 1.216(5) $\AA$ ). The average $\mathrm{C}-\mathrm{O}$ distances in 3,5 and 6 are consistent with reduction to single $\mathrm{C}-\mathrm{O}$ bonds. We note the disparity in the $\mathrm{C}-\mathrm{O}$ distances in 3 but do not think it is chemically significant. These metrics in 3, 5 and 6 are consistent with $\mathrm{pd}^{2-}$ and are essentially identical to those found in $\left[\mathrm{Ln}(\mathrm{tta})_{3}\left(N, N^{\prime}-O, O^{\prime}-\mathrm{pd}\right) \mathrm{Pt}\left(\mathrm{PPh}_{3}\right)_{2}\right](\mathrm{Ln}=\mathrm{Gd}, \mathrm{Er}){ }^{12}$

\section{EPR of $\left[\operatorname{Ln}(\text { hfac })_{3}\left(N, N^{\prime}-O, O^{\prime}-\right.\right.$ pd $\left.) V \mathbf{C p}^{\mathrm{R}}{ }_{2}\right]$}

The room temperature X-band EPR spectra of 3 and 5 shown in Fig. 7 are typical for $\mathrm{V}(\mathrm{IV})$ with an 8-line pattern from coupling of the electron $\operatorname{spin}(S=1 / 2)$ to the $I=7 / 2$ nuclear spin of the ${ }^{51} \mathrm{~V}$ (99.8\% abundance). The spectral simulation of 3 was gave $g_{\text {iso }}=1.9799$ and $A_{\text {iso }}=65.8 \times 10^{-4} \mathrm{~cm}^{-1}$, which are synonymous with non-oxo vanadyl species. ${ }^{40-42,44}$ In contrast, the spectrum of 5 exhibits the two overlapping 8-line signals; simulations yielded an equal mix of one entity with $g_{\text {iso }}=$ $1.9819, A_{\text {iso }}=68.4 \times 10^{-4} \mathrm{~cm}^{-1}$, and the other $g_{\text {iso }}=1.9779$ $A_{\text {iso }}=64.9 \times 10^{-4} \mathrm{~cm}^{-1}$ (Table 1$)$.

The corresponding frozen solution spectra recorded in toluene at $130 \mathrm{~K}$ clearly depicts a signal indicative of a single chemical species of $\mathbf{3}$ and $\mathbf{5}$ (Fig. 8). The simulation parameters are nearly identical, with $g=(1.9657,1.9776,1.9978)$ and $A=(106.6,78.1,11.0) \times 10^{-4} \mathrm{~cm}^{-1}$ for 3 , and $g=(1.9654$,

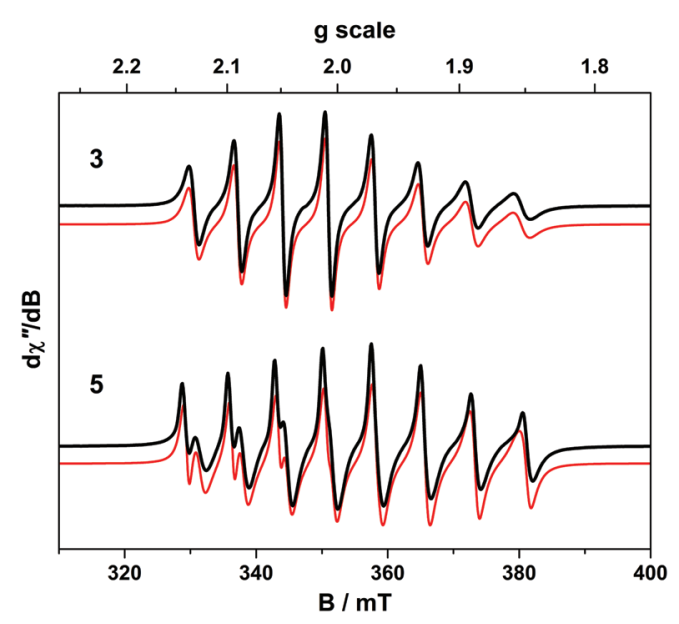

Fig. 7 X-band EPR spectra of 3 and 5 recorded in toluene solution at $293 \mathrm{~K}$ (experimental conditions: frequency, $9.8634 \mathrm{GHz}$; power, $0.63 \mathrm{~mW}$; modulation, $0.2 \mathrm{mT}$ ). Experimental data are represented by the black line; simulation is depicted by the red trace. 
Table 1 Spin-Hamiltonian $g$ - and $A$-values ${ }^{a}$ derived from spectral simulation of complexes

\begin{tabular}{llll}
\hline Complex & Spin centre & $g_{\text {iso }}$ & $A_{\text {iso }}$ \\
\hline 3 & $\mathrm{~V}(S=1 / 2)$ & 1.9799 & 65.8 \\
$\mathbf{5}$ & $\mathrm{V}^{b}(S=1 / 2)$ & 1.9819 & 68.4 \\
& $\mathbf{V}$ & 1.9790 & 64.9 \\
$\mathbf{4}$ & $\mathrm{V}(S=1 / 2)$ & 1.989 & - \\
& $\mathrm{Gd}(S=7 / 2)$ & 1.991 & - \\
& $\mathrm{Gd}(S=7 / 2)$ & 1.9779 & 72.0 \\
& $\mathrm{~V}^{b}(S=1 / 2)$ & 1.9950 & 72.0
\end{tabular}

${ }^{a}$ In $10^{-4} \mathrm{~cm}^{-1} \cdot{ }^{b}$ Major conformer. ${ }^{c}$ Minor conformer.

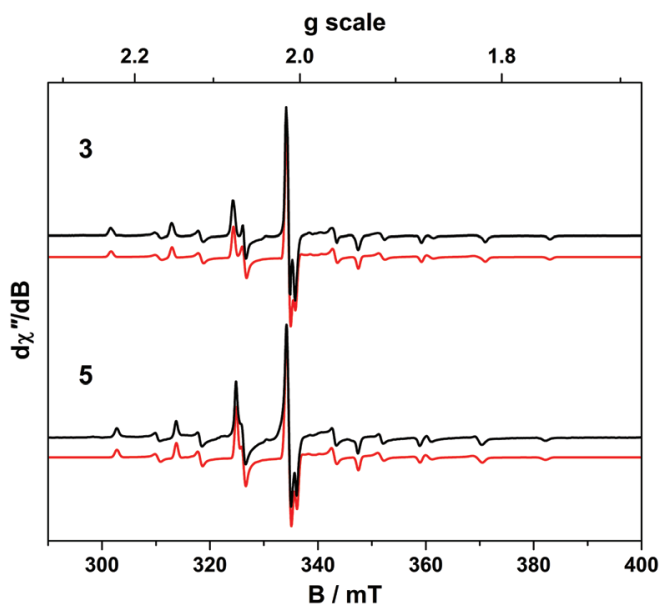

Fig. 8 X-band EPR spectra of 3 and 5 recorded in toluene solution at $130 \mathrm{~K}$ (experimental conditions: frequency, $9.4244 \mathrm{GHz}$; power, $0.2 \mathrm{~mW}$; modulation, $0.1 \mathrm{mT}$ ). Experimental data are represented by the black line; simulation is depicted by the red trace.

1.9794, 1.9978) and $A=(104.1,78.0,9.5) \times 10^{-4} \mathrm{~cm}^{-1}$ for 5. The existence of one signal in the frozen matrix suggests two conformations of $\mathbf{5}$ are present in fluid solution with subtle differences in their spin-Hamiltonian parameters. The spectral profile for 3 and 5 describes a ${ }^{2} \mathrm{~A}_{1}$ ground state $\left(\mathrm{d}_{x^{2}-y^{2}}\right.$ orbital in $C_{2 \mathrm{v}}$ symmetry) with archetypal $g_{x} \approx g_{y}<g_{z}<g_{\mathrm{e}}$ and $A_{x} \approx A_{y}>$ $A_{z}$ splitting patterns. ${ }^{38}$ The narrow lines neatly show a slight rhombicity in the spectrum with a notable inequivalence of $g_{x}$ and $g_{y}$, and $A_{x}$ and $A_{y}$ in this ligand field. This is in contrast to three-fold symmetric tris(chelate)vanadium complexes, which have the same ${ }^{2} \mathrm{~A}_{1}$ ground state but overall three-fold symmetry, such that $g_{x}=g_{y}$ and $A_{x}=A_{y} \cdot{ }^{38,41,42}$

The X-band EPR spectrum of $\mathbf{4}$ is shown in Fig. 9 and displays a superposition of the single broad signal for Gd(III) entwined with the 8-line pattern of $\mathrm{V}(\mathrm{IV})$. The spectrum was simulated with three subspectra, two of which arise from different conformations of the complex which are distinguished by the $g$-values of the V(Iv) centre because of the narrow linewidth as seen for 5. In 4 the major (10.5\%) and minor (1.8\%) conformer sum to a seventh of proportion of the intensity as expected for a heterobimetallic species with one $\operatorname{Gd}($ III) $S=7 / 2$

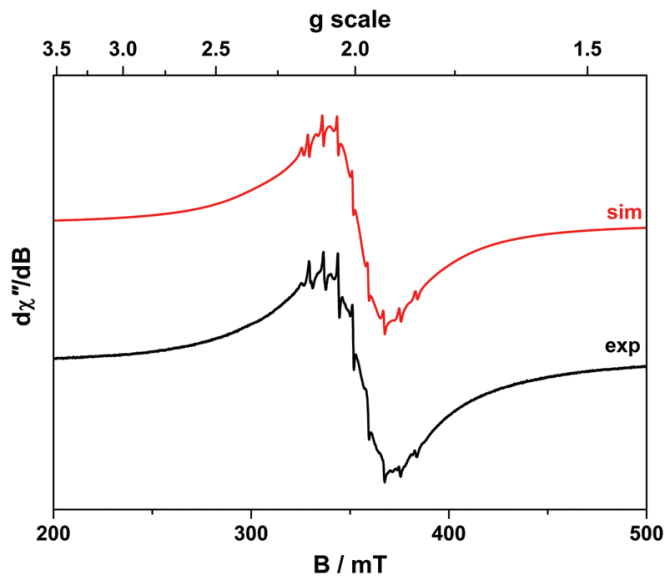

Fig. 9 X-band EPR spectrum of 4 recorded in toluene solution at $293 \mathrm{~K}$ (experimental conditions: frequency, $9.8717 \mathrm{GHz}$; power, $0.63 \mathrm{~mW}$; modulation, $0.3 \mathrm{mT}$ ). Experimental data are represented by the black line; simulation is depicted by the red trace.

ion and one V(Iv) $S=1 / 2$ ion. In addition we observe no manifestation of exchange coupling between the $\mathrm{Gd}(\mathrm{III})$ and $\mathrm{V}(\mathrm{Iv})$ centres such that $J \approx 0$ (i.e. two uncoupled spins).

\section{DFT calculations on 3}

Density functional theoretical (DFT) calculations were carried out on $3(S=1 / 2)$. The optimised structure is in excellent agreement with the crystallographic structures of both 3 and 5 (Table $\mathrm{S} 2 \dagger$ ). The computed $\mathrm{C}-\mathrm{C}$ and average $\mathrm{C}-\mathrm{O}$ bond distances of 1.391 and $1.336 \AA$, respectively, are representative of a bridging pd ligand in its dianionic (catecholate) form. The highest occupied molecule orbital (HOMO) is singly-occupied (SOMO) with 91\% vanadium $d$ character that depicts the $\mathrm{d}_{x^{2}-y^{2}}$ orbital which is $\mathrm{a}_{1}$ in $C_{2 \mathrm{v}}$ symmetry as shown by EPR (vide supra). The Mulliken spin population analysis shows + 1.35 spins ( $\alpha$-spin) located on the $\mathrm{V}(\mathrm{Iv})$ centre with matching $\beta$-spin on the first coordination sphere atoms (Fig. 10). This is the result of bond polarisation inherent to the relatively Lewis acidic $\mathrm{V}(\mathrm{IV})$ ion. $^{41}$

Time-dependent (TD) DFT calculations were carried out on 3 in order to assign the electronic spectra of this series of heterobimetallic compounds. Each complex (3-6) displays two

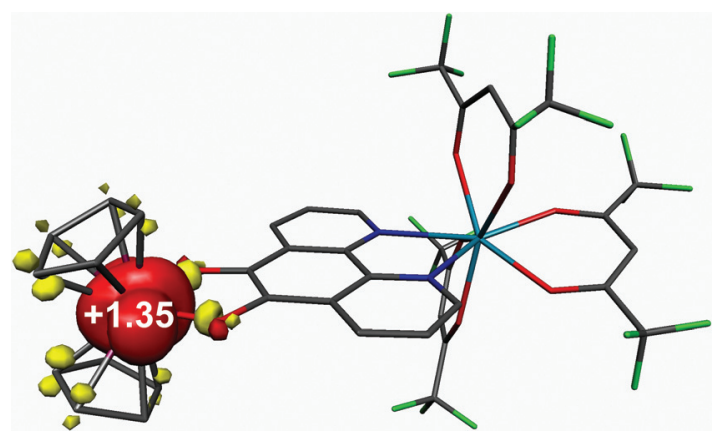

Fig. 10 Mulliken spin population analysis for 3. 


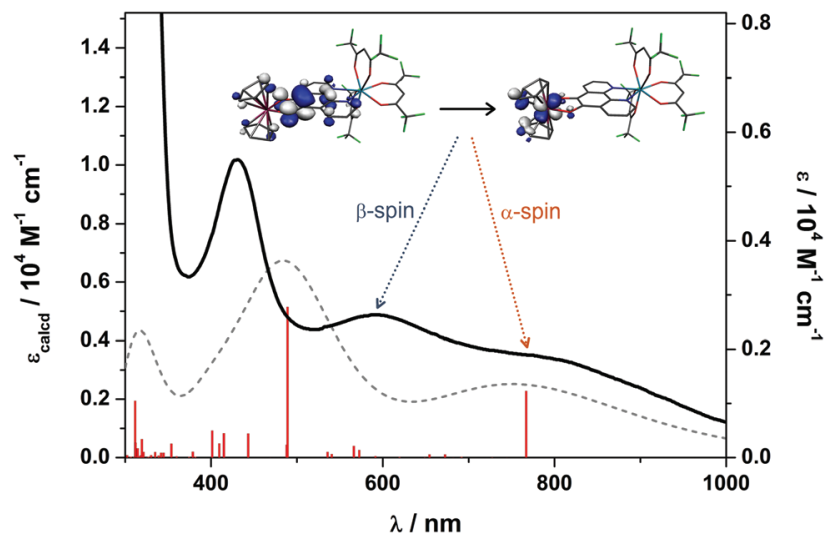

Fig. 11 Overlay of the experimental (solid line) and calculated (dashed line) electronic absorption spectra for 3 . The vertical bars show the individual calculated transitions. Inset orbitals depict the HOMO-1 $\rightarrow$ LUMO transition that constitutes the two lowest energy bands designated the $\alpha$-spin and $\beta$-spin excitations, respectively.

low-energy bands at ca. 800 and $600 \mathrm{~nm}$ (Fig. 4). These signature spectral features were well-reproduced in the TD-DFT analysis (Fig. 11). Both bands are ligand-to-metal charge transfer (LMCT) transitions between the same donor and acceptor orbitals. These are the $b_{2}$ symmetric HOMO-1, which is localised on the $O, O^{\prime}$ end of the pd bridging ligand, and the LUMO, which is the vanadium $d_{x y}$ orbital (Fig. 11). The computed spectrum reveals the spin-up ( $\alpha$-spin) excitation at $767 \mathrm{~nm}$ which perfectly matches the experimental peak at $800 \mathrm{~nm}$ in 3 . The corresponding spin-down ( $\beta$-spin) excitation appears at $489 \mathrm{~nm}$ which is $c a .100 \mathrm{~nm}$ blue shifted from the experimental peak. This aforementioned polarisation inherent to Lewis acidic V(Iv) sees the $\alpha$-spin manifold is exchange stabilised relative to the $\beta$-spin manifold by virtue of the unpaired electron in the $\mathrm{d}_{x^{2}-y^{2}}$ orbital. This is the same phenomenon that results in $>1$ spins located at the $\mathrm{V}$ (IV) centre in the spin population analysis (Fig. 10). The experimental polarisation is $0.54 \mathrm{eV}$ is overestimated by the calculations at $0.92 \mathrm{eV}$. This is typical for DFT as energies of virtual (unoccupied) orbitals are less reliable especially given the TD-DFT computed spectrum is derived from energy differences between donor and acceptor orbitals based on the ground state calculation. This neglects additional factors that can (de) stabilise excited states, and therein fail to accurately reproduce electronic spectra of paramagnetic compounds. Nevertheless, this approximation is sufficient to assign the observed spectral features. The prominent band at $410 \mathrm{~nm}$ is tentatively assigned as a $\pi \rightarrow \pi^{*}$ transition from the $\mathrm{pd}^{2-}$ ligand.

\section{Conclusions}

We have demonstrated the synthesis and first structural characterisation of $\left[\mathrm{Ln}(\mathrm{hfac})_{3}\left(N, N^{\prime}-\mathrm{pd}\right)\right]$ for both Y and Gd complexes. The synthetic route works in exactly the same way for both diamagnetic $\mathrm{Y}$ and paramagnetic Gd. Considering the size of Gd and Y, this synthetic route would be expected to be directly applicable to all the Ln elements from Sm-Lu. As the route is modular, a range of ancillary ligand environments would also be expected to be synthetically accessible. We have also shown the reduction of these coordination chemistry complexes using vanadocenes to form heterobimetallic rare earth-transition metal complexes. The spectroscopic data for $\left[\mathrm{Ln}(\mathrm{hfac})_{3}\left(N, N^{\prime}-O, O^{\prime}\right.\right.$-pd $\left.) \mathrm{VCp}^{\mathrm{R}}{ }_{2}\right]$ are consistent with oxidation of $\mathrm{V}$ (II) to $\mathrm{V}$ (IV) and reduction of $\mathrm{pd}$ to $\mathrm{pd}^{2-}$ in these complexes. This redox chemistry is driven by the $O, O^{\prime}$-pd binding of the $\operatorname{VCp}^{\mathrm{R}}{ }_{2}$ unit. Work is ongoing to isolate rare-earth transition metal complexes containing the radical anion of pd bridging the metal centres and to synthesise heterobimetallic $f-f^{\prime}$ complexes using $4 \mathrm{f}$ and $5 \mathrm{f}$ elements.

\section{Experimental}

\section{General details}

All air-sensitive manipulations were carried out in an MBraun glovebox $\left(\mathrm{O}_{2}\right.$ and $\left.\mathrm{H}_{2} \mathrm{O}<1 \mathrm{ppm}\right)$ or by using standard Schlenk techniques under $\mathrm{N}_{2}$. All glassware was dried at $130{ }^{\circ} \mathrm{C}$ overnight prior to use. Filter cannulas were prepared using Whatman $25 \mathrm{~mm}$ glass microfiber filters and were pre-dried at $130{ }^{\circ} \mathrm{C}$ overnight. Dry solvents were obtained using an Innovative Technology Inc. Pure Solv 400-5-MD solvent purification system (activated alumina columns). Solvents were sparged with $\mathrm{N}_{2}$ and stored in ampoules over activated molecular sieves under $\mathrm{N}_{2}$. Deuterated benzene and THF were dried by refluxing over K. Deuterated acetonitrile was dried by refluxing over $\mathrm{CaH}_{2}$. Dry deuterated solvents were degassed by three freeze-thaw cycles, vacuum distilled, and kept in ampoules in the glovebox under $\mathrm{N}_{2}$. The following starting materials were prepared according to literature procedures: $\mathrm{VCp}_{2}, \mathrm{VCp}_{2}^{\mathrm{t}}{ }^{46}$ Hexafluoroacetylacetone (Hhfac) was purchased from Aldrich and degassed by three freeze-thaw cycles before use. Potassium hydride in mineral oil was purchased from Aldrich, the mineral oil removed by washing with anhydrous hexanes, and stored under $\mathrm{N}_{2}$. $\mathrm{Ln}_{2} \mathrm{O}_{3}(\mathrm{Ln}=\mathrm{Y}, \mathrm{Gd})$, trifluoromethanesulfonic acid and 1,10-phenanthroline were purchased from Aldrich and used without further purification.

\section{Physical methods}

${ }^{1} \mathrm{H}$ NMR data were recorded on an AVIII $400 \mathrm{MHz}$ instrument and were referenced internally to the appropriate residual protio-solvent and are reported relative to tetramethylsilane $(\delta=0 \mathrm{ppm}) .{ }^{19} \mathrm{~F}$ and ${ }^{19} \mathrm{~F}\left\{{ }^{1} \mathrm{H}\right\}$ NMR spectra were recorded on a Bruker AVIII $400 \mathrm{MHz}$ spectrometer and were referenced to $\mathrm{CFCl}_{3}(\delta=0 \mathrm{ppm})$. All spectra were recorded at a constant temperature of $300 \mathrm{~K}$. Coupling constants $(J)$ are reported in hertz $(\mathrm{Hz})$. Standard abbreviations indicating multiplicity were used as follows: $\mathrm{m}=$ multiplet, $\mathrm{d}=$ doublet, $\mathrm{t}=$ triplet, $\mathrm{s}=$ singlet. UV/vis/NIR spectra were collected using a Shimadzu UV-3600 UV/vis/NIR spectrometer using anhydrous solvents, which were filtered through Celite ${ }^{\circledR}$ prior to use. ATR-IR spectra were collected using either a Shimadzu IRAffinity-1S or 
a Shimadzu FTIR 8400S spectrometer. Abbreviations indicating strength of bands were used as follows: $\mathrm{s}=$ strong, $\mathrm{m}=$ medium, $\mathrm{w}=$ weak .

Elemental analysis was performed at the University of Strathclyde, and a combustible (tungstic oxide) was used to ensure complete combustion of all complexes.

Crystallographic data were collected for single crystals of $\left[\mathrm{Y}(\mathrm{hfac})_{3}\left(N, N^{\prime} \text {-pd)] (1a/1b), [Y(hfac }\right)_{3}\left(N, N^{\prime}-O, O^{\prime}\right.\right.$-pd $\left.) \mathrm{VCp}_{2}\right](\mathbf{3})$ and $\left[\mathrm{Gd}(\mathrm{hfac})_{3}\left(N, N^{\prime}-O, O^{\prime}\right.\right.$-pd) $\left.\mathrm{VCp}_{2}^{\mathrm{t}}{ }_{2}\right]$ (6) on a Bruker D8 VENTURE diffractometer at $100 \mathrm{~K}$ using $\mathrm{Mo}-\mathrm{K} \alpha$ radiation $(\lambda=0.71073 \AA)$. Single-crystal structure data for $\left[\mathrm{Gd}(\mathrm{hfac})_{3}\left(N, N^{\prime}-\mathrm{pd}\right)\right] \cdot \mathrm{Et}_{2} \mathrm{O}(\mathbf{2 a})$, $\left[\mathrm{Gd}(\mathrm{hfac})_{3}\left(N, N^{\prime}-\mathrm{pd}\right)\right] \cdot$ Tol $(\mathbf{2 b})$ and $\left[\mathrm{Y}(\mathrm{hfac})_{3}\left(N, N^{\prime}-O, O^{\prime}-\mathrm{pd}\right) \mathrm{VCp}_{2}^{\mathrm{t}}{ }_{2}\right]$ (5) were collected by the EPSRC UK National Crystallography Service using a Rigaku AFC12 goniometer, mounted at the window of a FR-E+ SuperBright molybdenum rotating anode generator, and equipped with a (HG) Saturn724+ detector. CCDC numbers 1832429-1832434 and 1841191† contain the crystallographic information for this paper.

X-band EPR spectra were collected on a Bruker ELEXSYS E500 spectrometer and simulations were performed using Bruker's Xsophe software package. ${ }^{47}$

\section{Synthesis of $\left[\mathrm{Y}(\mathrm{hfac})_{3}\left(N, N^{\prime}-\mathrm{pd}\right)\right](1) \$$}

THF (15 mL) was added to a Schlenk flask charged with a dry mixture of $\mathrm{Y}(\mathrm{OTf})_{3}(1.16 \mathrm{~g}, 2.17 \mathrm{mmol})$, pd $(0.456 \mathrm{~g}$, $2.17 \mathrm{mmol}$ ) and $\mathrm{K}(\mathrm{hfac})(1.60 \mathrm{~g}, 6.51 \mathrm{mmol})$ at room temperature with stirring. The yellow suspension was stirred at room temperature for $1 \mathrm{~h}$, whereupon the solution became deep green. The green solution was stirred for $16 \mathrm{~h}$, THF was removed in vacuo and the green solids were extracted into toluene $(3 \times 5 \mathrm{~mL})$, giving a yellow solution. Removal of toluene in vacuo gave green solids, which were washed with hexane $(2 \times 5 \mathrm{~mL})$ to give $\left[\mathrm{Y}(\mathrm{hfac})_{3}\left(N, N^{\prime}\right.\right.$-pd $\left.)\right]$ as a pale green solid (1.70 g, $1.84 \mathrm{mmol}$, 85\% yield). Single crystals suitable for X-ray diffraction were grown from both a saturated $\mathrm{Et}_{2} \mathrm{O}$ solution at $-35{ }^{\circ} \mathrm{C}$ over 1 week $\left(\left[\mathrm{Y}(\mathrm{hfac})_{3}\left(N, N^{\prime}-\mathrm{pd}\right)\right] \cdot \mathrm{Et}_{2} \mathrm{O}, \mathbf{1 a}\right)$ and a saturated toluene solution at $-15{ }^{\circ} \mathrm{C}$ overnight $\left(\left[\mathrm{Y}(\mathrm{hfac})_{3}\left(N, N^{\prime}-\mathrm{pd}\right)\right] \cdot \mathrm{Tol}, \mathbf{1 b}\right) .{ }^{1} \mathrm{H}$ NMR $\left(\mathrm{C}_{6} D_{6}\right): \delta 6.23(3 \mathrm{H}, \mathrm{s}$, hfac-CH) $6.37\left(2 \mathrm{H}, \mathrm{dd}, J_{\mathrm{HH}}=7.8,5.5 \mathrm{~Hz}, \mathrm{pd} \mathrm{C}^{3,8}-\mathbf{H}\right) 7.53(2 \mathrm{H}, \mathrm{d}$, $\left.J_{\mathrm{HH}}=8.7 \mathrm{~Hz}, \mathrm{pd} \mathrm{C}^{4,7}-\mathbf{H}\right) 9.16\left(2 \mathrm{H}, \mathrm{d}, J_{\mathrm{HH}}=5.2 \mathrm{~Hz}, \mathrm{pd} \mathrm{C}^{2,9}-\mathbf{H}\right)$ ppm. ${ }^{19} \mathrm{~F}\left\{{ }^{1} \mathrm{H}\right\}$ NMR $\left(\mathrm{C}_{6} D_{6}\right): \delta-76.93\left(\mathrm{~s}\right.$, hfac-CF $\left.\underline{F}_{3}\right)$ ppm. Anal. calcd for $\mathrm{C}_{27} \mathrm{H}_{9} \mathrm{~N}_{2} \mathrm{O}_{8} \mathrm{~F}_{18} \mathrm{Y} \cdot \mathrm{C}_{7} \mathrm{H}_{8}: \mathrm{C}, 35.24 \% ; \mathrm{H}, 0.99 \% ; \mathrm{N}$, $3.04 \%$. Found: C, 35.06\%; H, 0.96\%; N, 3.14\%. IR(ATR) 1699 (w, $\left.\nu_{\mathrm{CO}}\right) 1668$ (w) 1647 (s) 1610 (w) 1579 (w) 1495 (m) 1426 (m) 1251 (s) 1197 (s) 1136 (s) 794 (s) 651 (s) 582 (m) cm cm $^{-1} \lambda_{\max }$ $(\mathrm{MeCN}) / \mathrm{nm}\left(\varepsilon / \mathrm{M}^{-1} \mathrm{~cm}^{-1}\right): 590(2300)$.

\section{Synthesis of $\left[\mathrm{Gd}(\mathrm{hfac})_{3}\left(N, N^{\prime}-\mathrm{pd}\right)\right](2)$}

THF (15 mL) was added to a Schlenk flask charged with a dry mixture of $\mathrm{Gd}(\mathrm{OTf})_{3}(0.759 \mathrm{~g}, 1.26 \mathrm{mmol}), \mathrm{K}(\mathrm{hfac})(0.997 \mathrm{~g}$, $3.77 \mathrm{mmol})$ and 1,10-phenanthroline-5,6-dione $(0.263 \mathrm{~g}$,

$\$$ We note that a complex formulated as $\left[\mathrm{Y}(\mathrm{hfac})_{3}\left(N, N^{\prime}-\mathrm{pd}\right)\right]$ was reported in the following paper, Chem. Papers, 2016, 70, 43. However, the spectroscopic data reported therein is not consistent with our full characterisation of compound 1 .
$1.25 \mathrm{mmol})$. The yellow suspension was stirred for $20 \mathrm{~h}$, turning green after ca. $1 \mathrm{~h}$. THF was removed in vacuo and $\left[\mathrm{Gd}(\mathrm{hfac})_{3}\left(N, N^{\prime}\right.\right.$-pd $\left.)\right]$ was extracted into toluene $(3 \times 10 \mathrm{ml})$ to give a yellow solution. Toluene was removed in vacuo to give a green solid, which was washed with hexanes to give $\left[\mathrm{Gd}(\mathrm{hfac})_{3}\left(N, N^{\prime}-\right.\right.$ pd)] as a pale green solid (0.992 g, $1.00 \mathrm{mmol}, 79 \%$ yield). Single crystals suitable for X-ray diffraction were grown from both saturated $\mathrm{Et}_{2} \mathrm{O}\left(\left[\mathrm{Gd}(\mathrm{hfac})_{3}\left(N, N^{\prime}-\mathrm{pd}\right)\right] \cdot \mathrm{Et}_{2} \mathrm{O}, 2 \mathrm{a}\right)$ and toluene $\left(\left[\mathrm{Gd}(\mathrm{hfac})_{3}\left(N, N^{\prime}-\mathrm{pd}\right)\right] \cdot \mathrm{Tol}, 2 \mathrm{~b}\right)$ solutions cooled to $-35^{\circ} \mathrm{C}$ overnight. Anal. calcd for $\mathrm{C}_{27} \mathrm{H}_{9} \mathrm{~N}_{2} \mathrm{O}_{8} \mathrm{~F}_{18} \mathrm{Gd} \cdot \mathrm{C}_{7} \mathrm{H}_{8}$ : C, 37.79\%; $\mathrm{H}$, $1.59 \%$; N, 2.59\%. Found: C, 37.58\%; H, 1.47\%; N, 2.54\%. IR (ATR): 1697 (w, $\left.\nu_{\mathrm{CO}}\right) 1661$ (w) 1647 (s) 1495 (m) 1252 (m) 1202 (m) 1142 (s) 1098 (w) 802 (s) 732 (m) 660 (s). $\lambda_{\max }$ $(\mathrm{MeCN}) / \mathrm{nm}\left(\varepsilon / \mathrm{M}^{-1} \mathrm{~cm}^{-1}\right): 597$ (129). $\mu_{\text {eff }}\left(298 \mathrm{~K}, d_{8}-\mathrm{THF}\right)$ 7.56-7.71 BM.

\section{Synthesis of $\left[\mathrm{Y}(\mathrm{hfac})_{3}\left(N, N^{\prime}-O, O^{\prime}-\mathrm{pd}\right) \mathrm{VCp}_{2}\right]$ (3)}

$\mathrm{Et}_{2} \mathrm{O}(10 \mathrm{~mL})$ was added to a $-78{ }^{\circ} \mathrm{C}$ cooled Schlenk flask charged with a dry mixture of $1(0.50 \mathrm{~g}, 0.54 \mathrm{mmol})$ and $\mathrm{VCp}_{2}$ $(0.10 \mathrm{~g}, 0.54 \mathrm{mmol})$, immediately giving a dark green solution. The reaction was allowed to warm to room temperature and stirred for $2 \mathrm{~h}$. $\mathrm{Et}_{2} \mathrm{O}$ was removed in vacuo and the green/black product recrystallised from toluene/hexane at $-15^{\circ} \mathrm{C}$ to give $\left[\mathrm{Y}(\mathrm{hfac})_{3}\left(N, N^{\prime}-O, O^{\prime}\right.\right.$-pd $\left.) \mathrm{VCp}_{2}\right]$ as a black microcrystalline solid $(0.335 \mathrm{~g}, 0.30 \mathrm{mmol}, 56 \%$ yield). Crystals suitable for X-ray diffraction were grown from a toluene/hexane mixture at $-35{ }^{\circ} \mathrm{C}$ overnight. Anal calcd For $\mathrm{C}_{37} \mathrm{H}_{19} \mathrm{~F}_{18} \mathrm{~N}_{2} \mathrm{O}_{8} \mathrm{VY}$ : C, 40.35\%; H, 1.74\%; N, 2.54\%. Found: C, 39.88\%; H, 1.81\%; N, 2.56\%. IR(ATR): 1651 (s) 1504 (m) 1371 (m, $\left.\nu_{\mathrm{CO}}\right) 1250$ (s) 1197 (s) 1134 (s) 794 (s) 651 (s) $582(\mathrm{~m}) \mathrm{cm}^{-1} . \lambda_{\max }(\mathrm{MeCN}) / \mathrm{nm}\left(\varepsilon / \mathrm{M}^{-1} \mathrm{~cm}^{-1}\right): 431$ (5400), 600 (2630), 788 (1840). $\mu_{\text {eff }}\left(298 \mathrm{~K}, d_{8}\right.$-THF): 1.71-1.74 BM.

\section{Synthesis of $\left[\mathrm{Gd}(\mathrm{hfac})_{3}\left(N, N^{\prime}-O, O^{\prime}-\mathrm{pd}\right) \mathrm{VCp}_{2}\right](4)$}

THF $(15 \mathrm{~mL})$ was added to a dry mixture of $\left[\mathrm{Gd}(\mathrm{hfac})_{3}\left(N, N^{\prime}-\right.\right.$ pd)] (500 mg, $0.505 \mathrm{mmol})$ and $\mathrm{V}(\mathrm{Cp})_{2}(91.3 \mathrm{mg}, 0.504 \mathrm{mmol})$ and the dark suspension was stirred for $24 \mathrm{~h}$. THF was removed in vacuo. $\quad\left[\mathrm{Gd}(\mathrm{hfac})_{3}\left(N, N^{\prime}-O, O^{\prime}-\mathrm{pd}\right) \mathrm{V}(\mathrm{Cp})_{2}\right]$ was extracted into toluene and cooled to $-15{ }^{\circ} \mathrm{C}$, whereupon it precipitated as a black powder (378 $\mathrm{mg}, 0.322 \mathrm{mmol}, 64 \%$ yield). Anal. calcd for $\mathrm{C}_{37} \mathrm{H}_{19} \mathrm{~F}_{18} \mathrm{~N}_{2} \mathrm{O}_{8}$ VGd: $\mathrm{C}, 37.99 \% ; \mathrm{H}, 1.64 \%$, 2.39\%. Found: C, 37.11\%; H, 1.70\%; N, 2.38\%. IR(ATR): 1651 (m) 1497 (m) 1381 (w, $\left.\nu_{\mathrm{CO}}\right) 1258$ (m) 1204 (w) 1134 (s) 1018 (s) 795 (s) 656 (m). $\lambda_{\max }(\mathrm{MeCN}) / \mathrm{nm}\left(\varepsilon / \mathrm{M}^{-1} \mathrm{~cm}^{-1}\right)$ : 425 (4650) 576 (3430) 797 (2740).

\section{Synthesis of $\left[\mathrm{Y}(\mathrm{hfac})_{3}\left(N, N^{\prime}-O, O^{\prime}-\mathrm{pd}\right) \mathrm{VCp}_{2}^{\mathrm{t}}\right](5)$}

$\mathrm{Et}_{2} \mathrm{O}(30 \mathrm{~mL})$ was added to a $-78{ }^{\circ} \mathrm{C}$ cooled Schlenk flask charged with $\mathrm{VCp}^{\text {tet }}(250 \mathrm{mg}, 0.83 \mathrm{mmol})$ and $\left[\mathrm{Y}(\mathrm{hfac})_{3}\left(N, N^{\prime}-\right.\right.$ pd)] (770 mg, $0.83 \mathrm{mmol}$ ), giving a dark green suspension. The reaction was allowed to warm to room temperature, and stirred for 16 hours. The dark suspension was filtered into a Schlenk and dried in vacuo to give deep-green solids, which were recrystallised from a saturated solution of toluene and hexane at $-15{ }^{\circ} \mathrm{C}$ overnight. The micro-crystals were isolated, washed with hexanes $(3 \times 15 \mathrm{~mL})$, and dried in vacuo to give $\left[\mathrm{Y}(\mathrm{hfac})_{3}\left(N, N^{\prime}-O, O^{\prime}-\mathrm{pd}\right) \mathrm{VCp}_{2}^{\mathrm{t}}\right.$ ] as a dark green powder $(520 \mathrm{mg}$, 
$10.43 \mathrm{mmol}, 50 \%$ yield). Crystals suitable for X-ray diffraction were grown by diffusion of hexane vapour into a toluene solution at $-35{ }^{\circ} \mathrm{C}$ over several days. Anal. calcd for $\mathrm{C}_{45} \mathrm{H}_{35} \mathrm{~F}_{18} \mathrm{~N}_{2} \mathrm{O}_{8} \mathrm{VY}: \mathrm{C}, 44.54 \%$; H, 2.91\%; N, 2.31\%. Found: C, 44.49\%; H, 3.78\%; N, 2.49\%. IR(ATR): 1651 (s), 1506 (m), $1373\left(\mathrm{~m}, \nu_{\mathrm{CO}}\right), 1250(\mathrm{~s}), 794(\mathrm{~m}), 727(\mathrm{w}), 659(\mathrm{~m}) . \lambda_{\max }$ (THF)/nm ( $\left(\varepsilon / \mathrm{M}^{-1} \mathrm{~cm}^{-1}\right): 418$ (6970), 553 (2920), 816 (2340). $\mu_{\text {eff }}\left(298 \mathrm{~K}, d_{8}\right.$-THF) 1.72-1.75 BM.

\section{Synthesis of $\left[\mathrm{Gd}(\mathrm{hfac})_{3}\left(\mathrm{~N}, \mathrm{~N}^{\prime}-\mathrm{O}, \mathrm{O}^{\prime}-\mathrm{pd}\right) \mathrm{VCp}_{2}^{\mathrm{t}}\right]$ (6)}

$\mathrm{Et}_{2} \mathrm{O}(30 \mathrm{~mL})$ was added to a $-78{ }^{\circ} \mathrm{C}$ cooled Schlenk flask charged with $\operatorname{VCp}_{2}^{\text {tet }}(38 \mathrm{mg}, 0.13 \mathrm{mmol})$ and $\left[\mathrm{Gd}(\mathrm{hfac})_{3}\left(N, N^{\prime}-\right.\right.$ pd)] (130 mg, $0.13 \mathrm{mmol}$ ), giving a dark green suspension. The reaction was allowed to warm to room temperature, and stirred for 16 hours. The dark suspension was filtered into a Schlenk and dried in vacuo to give deep-green solids, which were recrystallised from a saturated solution of toluene and hexane at $-15{ }^{\circ} \mathrm{C}$ overnight. The micro-crystals were isolated, washed with hexanes $(3 \times 15 \mathrm{~mL})$, and dried in vacuo to give $\left[\mathrm{Gd}(\mathrm{hfac})_{3}\left(N, N^{\prime}-\right.\right.$ $O, O^{\prime}$-pd) $\mathrm{VCp}_{2}^{\mathrm{t}}$ ] as a dark green powder (70 mg, $5.40 \mathrm{mmol}, 42 \%$ yield). Crystals suitable for X-ray diffraction were grown by diffusion of hexane vapour into an $\mathrm{Et}_{2} \mathrm{O}$ solution at $-35{ }^{\circ} \mathrm{C}$ over several days. Anal. calcd for $\mathrm{C}_{45} \mathrm{H}_{35} \mathrm{~F}_{18} \mathrm{~N}_{2} \mathrm{O}_{8}$ VGd: C, 42.16\%; H, 2.75\%; N, 2.19\%. Found: C, 42.45\%; H, 3.18\%; N, 2.04\%. IR(ATR): 1650 (s), $1500(\mathrm{~m}), 1370$ (w, $\left.\nu_{\mathrm{CO}}\right), 1250(\mathrm{~s}), 800(\mathrm{~m})$, $733(\mathrm{w}), 662(\mathrm{~m}) . \lambda_{\max }(\mathrm{THF}) / \mathrm{nm}\left(\varepsilon / \mathrm{M}^{-1} \mathrm{~cm}^{-1}\right): 435$ (6260), 792 (1420). $\mu_{\text {eff }}\left(298 \mathrm{~K}, d_{8}\right.$-THF) 7.99-8.41 BM.

\section{Conflicts of interest}

There are no conflicts to declare.

\section{Acknowledgements}

We acknowledge the EPSRC for PhD studentships to JRH (EP/ L504786/1) and SJH (EP/M508056/1), Imperial College London (JRF to JHF) and the University of Glasgow for funding. We thank Professor Nick Long for his mentorship while at ICL and for useful discussions. We also acknowledge the EPSRC UK National Crystallography Service at the University of Southampton.

\section{References}

1 J. F. Berry and C. M. Thomas, Dalton Trans., 2017, 46, 5472-5473.

2 K. Liu, W. Shi and P. Cheng, Coord. Chem. Rev., 2015, 289-290, 74-122.

3 K. Griffiths, A. C. Tsipis, P. Kumar, O. P. E. Townrow, A. Abdul-Sada, G. R. Akien, A. Baldansuren, A. C. Spivey and G. E. Kostakis, Inorg. Chem., 2017, 56, 9563-9573.

4 J. D. Rinehart, M. Fang, W. J. Evans and J. R. Long, J. Am. Chem. Soc., 2011, 133, 14236-14239.
5 S. Demir, L.-R. Jeon, J. R. Long and T. D. Harris, Coord. Chem. Rev., 2015, 289-290, 149-176.

6 C. A. P. Goodwin, F. Ortu, D. Reta, N. F. Chilton and D. P. Mills, Nature, 2017, 548, 439-442.

7 F.-S. Guo, B. M. Day, Y.-C. Chen, M.-L. Tong, A. Mansikkamäki and R. A. Layfield, Angew. Chem., Int. Ed., 2017, 56, 11445-11449.

8 A. E. Friedman, J.-C. Chambron, J.-P. Sauvage, N. J. Turro and J. K. Barton, J. Am. Chem. Soc., 1990, 112, 4960-4962.

9 K. Peuntinger, T. D. Pilz, R. Staehle, M. Schaub, S. Kaufhold, L. Petermann, M. Wunderlin, H. Görls, F. W. Heinemann, J. Li, T. Drewello, J. G. Vos, D. M. Guldi and S. Rau, Dalton Trans., 2014, 43, 13683-13695.

10 C. A. Goss and H. D. Abruna, Inorg. Chem., 1985, 24, 42634267.

11 J. Yuasa, T. Suenobu and S. Fukuzumi, J. Phys. Chem. A, 2005, 109, 9356-9362.

12 N. M. Shavaleev, L. P. Moorcraft, S. J. A. Pope, Z. R. Bell, S. Faulkner and M. D. Ward, Chem. - Eur. J., 2003, 9, 52835291.

13 A. Y. Girgis, Y. S. Sohn and A. L. Balch, Inorg. Chem., 1975, 14, 2327-2331.

14 G. A. Fox, S. Bhattacharya and C. G. Pierpont, Inorg. Chem., 1991, 30, 2895-2899.

15 W. Paw and R. Eisenberg, Inorg. Chem., 1997, 36, 2287-2293.

16 F. Calderazzo, F. Marchetti, G. Pampaloni and V. Passarelli, J. Chem. Soc., Dalton Trans., 1999, 4389-4396.

17 E. K. Brechin, L. Calucci, U. Englert, L. Margheriti, G. Pampaloni, C. Pinzino and A. Prescimone, Inorg. Chim. Acta, 2008, 361, 2375-2384.

18 F. Calderazzo, G. Pampaloni and V. Passarelli, Inorg. Chim. Acta, 2002, 330, 136-142.

19 F. Calderazzo and G. Pampaloni, J. Organomet. Chem., 1987, 330, 47-59.

20 N. M. Shavaleev, L. P. Moorcraft, S. J. A. Pope, Z. R. Bell, S. Faulkner and M. D. Ward, Chem. Commun., 2003, 11341135.

21 S. Kobayashi, M. Suguira, H. Kitagawa and W. W.-L. Lam, Chem. Rev., 2002, 102, 2227-2302.

22 K. D. Pollard, H. A. Jenkins and R. J. Puddephatt, Chem. Mater., 2000, 12, 701-710.

23 G. Malandrino, R. L. Nigro, I. L. Fragala and C. Benelli, Eur. J. Inorg. Chem., 2004, 500-509.

24 I. V. Taidakov, Y. A. Strelenko, R. S. Borisov, A. Z. Temerdashev, N. P. Datskevich and A. G. Vitukhnovskii, Russ. J. Coord. Chem., 2015, 41, 230239.

25 M. Hardiman, J. Pellisson, S. E. Barnes, P. E. Bisson and M. Peter, Phys. Rev. B: Condens. Matter Mater. Phys., 1980, 22, 2175-2194.

26 D. Roitershtein, A. Domingos, L. C. J. Pereira, J. R. Ascenso and N. Marques, Inorg. Chem., 2003, 42, 7666-7673.

27 V. S. Herzog and K. Gustav, Z. Anorg. Allg. Chem., 1966, 346, 150-161.

28 J.-W. Dai, Z.-Y. Li and O. Sato, Acta Crystallogr., Sect. E: Struct. Rep. Online, 2014, 70, 0573. 
29 A. Y. Rogachev, A. V. Mironov, S. I. Troyanov, N. P. Kuzmina and A. V. Nemukhin, J. Mol. Struct., 2006, 789, 187-194.

30 R. D. Shannon, Acta Crystallogr., Sect. A: Cryst. Phys., Diffr., Theor. Gen. Crystallogr., 1976, 32, 751-767.

31 M. Wen, E. Kejia, M. Munakata, Y. Suenaga, T. KurodaSowa, M. Maekawa and S. G. Yan, Mol. Cryst. Liq. Cryst., 2006, 457, 203-213.

32 D. M. Murphy, K. McNamara, P. Richardson, V. SanchezRomaguera, R. E. P. Winpenny and L. J. Yellowlees, Inorg. Chim. Acta, 2011, 374, 435-441.

33 F. Ortu, J. Liu, M. Burton, J. M. Fowler, A. Formanuik, N. F. Chilton, M-E. Boulon and D. P. Mills, Inorg. Chem., 2017, 56, 2496-2505.

34 N. G. Connelly and W. E. Geiger, Chem. Rev., 1996, 96, 877910.

35 J. D. L. Holloway and W. E. Geiger Jr., J. Am. Chem. Soc., 1979, 101, 2038-2044.

36 W. J. Evans, Organometallics, 2016, 35, 3088-3100.

37 J. L. Petersen and L. Griffith, Inorg. Chem., 1980, 19, 18521858.
38 J. L. Petersen and L. F. Dahl, J. Am. Chem. Soc., 1975, 97, 6422-6432.

39 D. P. Bakalik and R. G. Hayes, Inorg. Chem., 1972, 11, 17341738.

40 J. A. Belot, R. D. McCullough, A. L. Rheingold and G. P. A. Yap, Organometallics, 1996, 15, 5062-5065.

41 B. Gleeson, J. Claffey, M. Hogan, H. Müller-Bunz, D. Wallis and M. Tacke, J. Organomet. Chem., 2009, 694, 1369-1374.

42 P. Ghosh, S. Ghosh, C. Navara, R. K. Narla, A. Benyumov and F. M. Uckun, J. Inorg. Biochem., 2001, 84, 241-253.

43 G. H. Spikes, S. Sproules, E. Bill, T. Weyhermu and K. Wieghardt, Inorg. Chem., 2008, 47, 10935-10944.

44 S. R. Cooper, Y. B. Koh and K. N. Raymond, J. Am. Chem. Soc., 1982, 104, 5092-5102.

45 C. Zixiang, Z. Linli, L. Xiaoming, Y. Hongtao and L. Bing, Z. Anorg. Allg. Chem., 2012, 638, 1523-1530.

46 L. E. Manzer, E. A. Mintz and T. J. Marks, Inorg. Synth., 1989, 28, 260-263.

47 G. R. Hanson, K. E. Gates, C. J. Noble, M. Griffin, A. Mitchell and S. Benson, J. Inorg. Biochem., 2004, 98, 903-916. 